Coleman, G. S. (1960). J. gen. Microbiol. 22, 555-563

\title{
The Gultivation of Sheep Rumen Oligotrich Protozoa in vitro
}

\author{
BY G. S. COLEMAN \\ Agricultural Research Council, Institute of Animal Physiology, \\ Babraham, Cambridge
}

\begin{abstract}
SUMMARY : Oligotrich protozoa from the sheep rumen, principally Entodinium caudatum, were maintained in culture in vitro and dividing every 2 days at a density of 15,000-30,000 protozoa/ml. for 18 months on a medium of rice starch, dried grass, $10 \%(\mathrm{v} / \mathrm{v})$ rumen fluid (fresh or autoclaved) and $50 \mu \mathrm{g}$. chloramphenicol $/ \mathrm{ml}$. The effect on these organisms of varying each of these factors in turn and the use of different growth conditions is described. The protozoa have also been grown from an inoculum of $100-900 / \mathrm{ml}$. to a density of over $50,000 / \mathrm{ml}$. in 10 days.
\end{abstract}

Many unsuccessful attempts to cultivate rumen protozoa in vitro have been made in the last hundred years; the earlier attempts were summarized by Becker, Schultz \& Emmerson (1929). Margolin (1930) and Westphal (1934) achieved some success in the cultivation of oligotrich protozoa, but the first real advance was made by Hungate $(1942,1943)$ who maintained some species of cattle oligotrich ciliates alive for over a year. Sugden (1953) was unable to maintain oligotrich protozoa from the sheep alive for more than 15 days, whereas Kandatsu \& Takahashi $(1955 a, b, 1956)$ kept Entodinia spp. from goats alive for over 30 days with some multiplication. The purpose of the present paper is to describe experiments in which Entodinia spp., principally Entodinium caudatum from sheep rumen, have been maintained with frequent division for over 18 months; a preliminary communication has already appeared (Coleman, 1958).

\section{METHODS}

Media. The standard medium consisted of $30 \mathrm{ml}$. quantities of autoclaved mineral salts solution (Coleman, 1958) to which was added: $\mathrm{Na}_{2} \mathrm{~S} .9 \mathrm{H}_{2} \mathrm{O}$ to a final concentration of $0.01 \%(\mathrm{w} / \mathrm{v}) ; c .15 \mathrm{mg}$. dried grass $\left(55^{\circ}\right.$ for 3 days $)$ finely ground in a Lee Attrition Mill (Lee Engineering Co., Milwaukee, Wis., U.S.A.); $15 \mathrm{mg}$. rice starch, added as a suspension of known concentration in water; $\mathbf{3} .0 \mathrm{ml}$. prepared fresh rumen fluid; chloramphenicol to a final concentration of $50 \mu \mathrm{g} . / \mathrm{ml}$. The final volume of complete medium was $c .35 \mathrm{ml}$. Tubes of complete medium were gassed vigorously for $3 \mathrm{~min}$. with a mixture of $95 \%$ $(\mathrm{v} / \mathrm{v}) \mathrm{N}_{2}+5 \%(\mathrm{v} / \mathrm{v}) \mathrm{CO}_{2}$ (which had been freed from oxygen by the method of Stone \& Beeson, 1936) and stoppered immediately. All media were warmed to $38^{\circ}$ before use. Fresh rumen fluid was usually prepared and used the same day (see Coleman, 1958), except when it was inconvenient to obtain fresh rumen contents. At these times the prepared material was kept at $-15^{\circ}$ under $95 \%(\mathrm{v} / \mathrm{v}) \mathrm{N}_{2}+5 \%(\mathrm{v} / \mathrm{v}) \mathrm{CO}_{2}$ for not longer than 4 days and warmed to $38^{\circ}$ 
before use. Autoclaved rumen fluid was prepared by autoclaving (10 lb./sq.in. for 20 min.) fresh rumen fluid in sealed McCartney bottles under $95 \%(\mathrm{v} / \mathrm{v})$ $\mathrm{N}_{2}+5 \%(\mathrm{v} / \mathrm{v}) \mathrm{CO}_{2}$.

Cultural conditions. The procedures involved in the initial inoculation from fresh rumen contents and the subsequent manipulations that resulted in cultures of oligotrich protozoa which divided every 2-4 days have already been described (Coleman, 1958). The conditions used in the experiments described below differed initially in that the cultures were divided every $48 \mathrm{hr}$. regardless of the number of protozoa present. Later, maintenance was further simplified by omitting the preliminary centrifugation and replacement of supernatant fluid on days when the cultures were diluted with an equal volume of fresh medium (i.e. growth occurred under condition B 2-see below).

All experiments were carried out in $50 \mathrm{ml}$. centrifuge tubes containing c. $35 \mathrm{ml}$. medium, gassed with $\mathrm{O}_{2}$-free $95 \% \mathrm{~N}_{2}+5 \% \mathrm{CO}_{2}$ gas mixture, sealed with a rubber bung and incubated at $38^{\circ}$. The time taken for all manipulations during which cultures had to be out of the incubator was kept to a minimum.

For the successful maintenance of the protozoa it was necessary to add every day fresh rice starch and grass with or without the other medium constituents. Cultures were diluted with an equal volume of fresh medium every 1-4 days, depending on the conditions, and the diluted cultures then divided each to make two identical cultures (this process is hereafter referred to as 'dilution' of a culture and the day on which it was carried out as a 'dilution day'). All the experiments described were carried out on one member of such a pair of tubes, the other serving as a control.

Four different growth conditions were used. The manipulations on days when the culture was diluted and on days when the volume was not changed, i.e. non-dilution days, were carried out as follows.

Condition $A$. Non-dilution day: culture centrifuged, supernatant fluid removed and replaced by an equal volume of fresh medium. Dilution day: culture centrifuged, supernatant fluid removed and replaced by twice its volume of fresh medium.

Condition $B$. Non-dilution day: culture centrifuged, supernatant fluid removed and replaced by an equal volume of fresh medium. Dilution day: culture diluted with an equal volume of fresh medium.

Condition $C$. Non-dilution day: rice starch (to same concentration as on dilution day) and $15 \mathrm{mg}$. dried grass added only. Dilution day: culture centrifuged, supernatant fluid removed and replaced by twice its volume of fresh medium containing rice starch and grass.

Condition $D$. Non-dilution day: rice starch and $15 \mathrm{mg}$. dried grass added only. Dilution day: culture diluted with equal volume of fresh medium containing rice starch and grass.

All centrifugation was at $500 \mathrm{~g}$ for $2 \mathrm{~min}$. (this did not affect the motility and viability of the protozoa). The initial concentration of all medium constituents in fresh tubes of medium was adjusted so that at the end of the manipulation the concentration of the fresh constituents was that in the medium under test, except that on dilution days under conditions $B$ and $D$, 
the concentration of freshly added chloramphenicol and rumen fluid (when present) was half that added on non-dilution days. The frequency of dilution of the culture under any growth condition is given in days by the number after the letter, e.g. A2.

The number of protozoa was estimated by the method of Coleman (1958); unless otherwise stated the numbers quoted always refer to the numbers of protozoa present immediately before the dilution of a culture. Where the effect of a change in growth conditions is reported, at least 3 weeks was allowed to elapse before the number of protozoa present was estimated.

\section{RESULTS}

It was shown by Coleman (1958) that for the continued growth of rumen oligotrich protozoa it was necessary to add rice starch, dried grass, chloramphenicol and fresh rumen fluid to the basal mineral salts (i.e. standard medium) and that when the supernatant fluid was not replaced every $24 \mathrm{hr}$. by fresh complete medium the protozoa soon died. In the initial stages of this work, i.e. after 40 dilutions, when the cultures were diluted (condition A) every

Table 1. Steady state population densities of Entodinia spp. under various growth conditions

The medium consisted of $30 \mathrm{ml}$. basal mineral salts containing $0.01 \% \mathrm{Na}_{2} \mathrm{~S} .9 \mathrm{H}_{2} \mathrm{O}+$ the materials indicated: $\mathbf{R}=0.5 \mathrm{mg}$. rice $\operatorname{starch} / \mathrm{ml}$.; $\mathbf{R} / 2=0.25 \mathrm{mg}$. rice $\operatorname{starch} / \mathrm{ml}$.; $\mathbf{G}=c$. $15 \mathrm{mg}$. dried grass $/ \mathrm{ml}$; FRF $=10 \%$ fresh rumen fluid; $\mathbf{A R F}=10 \%$ autoclaved rumen fluid; CAP $=50 \mu \mathrm{g}$. chloramphenicol $/ \mathrm{ml}$. For growth conditions see text.

\section{Medium}

1. R, G, FRF, CAP

2. R/2, G, FRF, CAP

3. R, G, FRF, CAP

4. $R, G, F R F, C A P$

5. $\mathrm{R} / 2, \mathrm{G}, \mathrm{FRF}, \mathrm{CAP}$

6. $\mathbf{R}\left(120^{\circ}, 24 \mathrm{hr}\right.$.) $\mathbf{G}$ (autoclaved), FRF, CAP

7. R/2, G, ARF, CAP

8. R/2, G, ARF, CAP

9. R/2, G, $1 \%$ ARF, CAP

10. $R / 2\left(120^{\circ}, 24 \mathrm{hr}\right.$.), $\mathrm{G}$ (autoclaved), ARF, CAP

11. R, G

No. of dilutions Population density under that immediately before growth dilution condition (protozoa $/ \mathrm{ml}$.)

Growth
condition

A2

A2

B 2

D2

$\mathrm{D}$ (dil. 3 days out of 4)

B2

A2

C2

C2

$\mathrm{C2}$

D3

40
16
155
53
70
117

17
171
32
95

53
28,000

13,000

32,000

14,000

4000 before third successive dilution 26,000

$16,000-26,000$

24,000

10,000

18,000

14,000

2-4 days, the predominant organisms were morphologically similar to Entodinium caudatum and $E$. longinucleatum as described by Bhatia (1936), but variable numbers of Metadinium medium and $E$. simplex were also present. It is possible that, as was pointed out by Sugden (1953), the small $E$. simplex could not ingest rice starch grains and was living on the other medium constituents. Latterly, however, after 150 dilutions under condition B2, over $99 \%$ of the organisms were $\boldsymbol{E}$. caudatum. All the experiments were carried 
out with cultures containing over $90 \%$ E. caudatum and only $\boldsymbol{E}$. caudatum and $E$. longinucleatum were included in the numbers reported. The detailed effect of varying in turn each material in the standard medium under condition A2 or $\mathrm{B} 2$ is shown below.

Rice starch. The optimum concentration of rice starch was $0.5 \mathrm{mg} . / \mathrm{ml}$. and with growth occurring under condition A 2, 28,000 organisms $/ \mathrm{ml}$. were present (Table 1). When the amount of starch was halved there were only 13,000 protozoa $/ \mathrm{ml}$.; doubling the starch concentration produced an initial increase in numbers which was followed by a steady decrease, probably associated with an increase in the number of bacteria. Omission of the rice starch resulted in death of the protozoa within 3 days. The rice starch was not replaceable by soluble starch or autoclaved rice starch, although in the presence of the latter a steadily decreasing number of organisms persisted for 46 days (100 protozoa/ml. after 15 dilutions).

The effect of heating the rice starch was investigated as it was hoped to be able to grow the protozoa in axenic culture by using sterile starch. When the dry starch was heated in an oven to $160^{\circ}$ for $1 \mathrm{hr}$. before use, the protozoa soon died. Heating the starch at $140^{\circ}$ for $1 \mathrm{hr}$. did not affect the protozoa when the numbers exceeded $15,000-20,000 / \mathrm{ml}$. but resulted in their death when there were less than $5000-10,000 / \mathrm{ml}$. The method eventually found to have least effect on the protozoa was to heat the dry starch in an oven at $120^{\circ}$ for $24 \mathrm{hr}$.

Dried grass. Omission of the dried grass was followed by the death of the organisms within ten days when the culture was diluted normally; when the culture was not diluted small numbers of protozoa (i.e. 5000 protozoa $/ \mathrm{ml}$.) occasionally persisted for over 50 days. Solka Floc (Johnsen, Jörgensen \& Wettre, Ltd., 26 Farringdon Street, London, E.C. 4) completely replaced the dried grass for 4 days, but thereafter the number of protozoa declined as in the absence of grass. The dried grass was not replaceable by $0.5 \mathrm{ml}$. of the supernatant fluid obtained after autoclaving $1 \mathrm{~g}$. dried grass in $20 \mathrm{ml}$. water. The grass could be sterilized by autoclaving in the $30 \mathrm{ml}$. quantities of basal salts or in McCartney bottles after damping with water. The use of grass sterilized in either manner produced an initial depression in the growth rate of the protozoa, but this slowly improved to that of the original culture. After a 6-month period of adaptation cultures were obtained which grew almost as well on grass + rice starch sterilized as described above as on unsterile rice starch + grass (Table 1). The use of rice starch and dried grass dry-heated at $140^{\circ}$ for $1 \mathrm{hr}$. before use produced erratic results with no or only slow growth, sometimes followed by death of the protozoa.

Chloramphenicol. The optimum concentration of chloramphenicol was $50 \mu \mathrm{g} . / \mathrm{ml}$.; an increase to $150 \mu \mathrm{g} . / \mathrm{ml}$. killed the protozoa. When the antibiotic was omitted, the organisms grew normally for 3-4 days but then, even when the culture was not diluted, the numbers decreased and the protozoa died or were present in small numbers. Under these conditions the bacterial growth was much heavier than in the presence of chloramphenicol and this may have been the cause of the failure of the protozoa to grow. 
Rumen fluid. When the fresh rumen fluid was omitted, the protozoa grew normally for 3-4 days and then, in the absence of further dilution of the culture, the numbers steadily decreased. When fresh rumen fluid was replaced by an equal volume of autoclaved rumen fluid, the culture could still be maintained under condition A2 with 16,000-26,000 protozoa $/ \mathrm{ml}$. in the presence of only $0 \cdot 25 \mathrm{mg}$. rice starch $/ \mathrm{ml}$. which was the optimum concentration under these conditions (Table 1). An increase in rice starch to $0.5 \mathrm{mg} . / \mathrm{ml}$. increased the bacterial growth without improving the protozoal growth and this heavier bacterial growth was occasionally associated with sudden death of the protozoa. Reproducible growth in the presence of $10 \%(\mathrm{v} / \mathrm{v})$ autoclaved rumen fluid under condition $\mathrm{A} 2$ was difficult to attain and the cultures often contained many dead protozoa; with condition $\mathrm{C} 2$ consistent growth with 24,000 protozoa $/ \mathrm{ml}$. was obtained. Condition $\mathrm{C2}$ was hereafter adopted for all experiments with autoclaved rumen fluid. Decrease of the autoclaved rumen fluid concentration from $10 \%(\mathrm{v} / \mathrm{v})$ to $1 \%$ decreased the number of protozoa to $10,000 / \mathrm{ml}$.

No systematic attempts to estimate the number or types of bacteria present were made, but when serial tenfold dilutions of the complete culture plus protozoa grown on $10 \%(\mathrm{v} / \mathrm{v})$ autoclaved rumen fluid under condition C2 were made in the starch yeast extract tryptose medium of McPherson (1953) and the cultures incubated aerobically, over $10^{6} \mathrm{bacteria} / \mathrm{ml}$. were found.

In an attempt to determine whether it was the supernatant fluid or the bacterial bodies which was the essential part of the autoclaved rumen fluid, fresh rumen fluid was fractionated as follows. Fresh rumen fluid prepared in the normal way was centrifuged at $30,000 \mathrm{~g}$ for $50 \mathrm{~min}$. and the supernatant fluid removed. The deposit (bacterial bodies fraction) was washed twice on the centrifuge with basal salts solution and made up with basal salts solution to the same volume as the original rumen fluid. The two fractions were autoclaved in sealed McCartney bottles under a gas mixture of $95 \%(\mathrm{v} / \mathrm{v}) \mathrm{N}_{2}+5 \%(\mathrm{v} / \mathrm{v})$ $\mathrm{CO}_{2}$ and tested at a concentration of $10 \%(\mathrm{v} / \mathrm{v})$ under condition $\mathrm{C2}$. The autoclaved rumen fluid was replaceable by the supernatant fluid fraction for a period exceeding 80 days, although the number of organisms was $10-40 \%$ lower. The bacterial bodies fraction replaced the autoclaved rumen fluid completely for 15 days, but thereafter the number of protozoa decreased steadily until there were only 300 protozoa $/ \mathrm{ml}$. after 30 days.

In the presence of $10 \%(\mathrm{v} / \mathrm{v})$ autoclaved rumen fluid the use of sterile grass and rice starch instead of nonsterile material decreased the number of protozoa to $18,000 / \mathrm{ml}$. (cf. $24,000 / \mathrm{ml}$.).

Rumen fluid and chloramphenicol. When $15 \mathrm{mg}$. rice starch $+15 \mathrm{mg}$. dried grass was added each day for a week to a standard culture after dilution, containing e.g. 16,000 protozoa $/ \mathrm{ml}$., without replacing the supernatant fluid, the number of protozoa increased to $36,000 / \mathrm{ml}$. and could then be maintained by treatment under condition D3 (Table 1). Under these conditions the bacterial growth was much heavier than in the presence of fresh rumen fluid and chloramphenicol. Attempts to increase the dilution rate of the culture to every 2 days were unsuccessful as the culture eventually died out. 
Temperature. 'The usual growth temperature was $38^{\circ}$; incubation at $41^{\circ}$ resulted in the formation of distorted protozoa which died within 14 days, whether or not the culture was diluted. When incubated at $33^{\circ}$, the protozoa died within 4 days.

Basal mineral salts. Replacement of the potassium in the basal mineral salts solution by an equimolar concentration of sodium while growth was occurring under condition B2 produced a temporary $50 \%$ decrease in the number of protozoa, but after 30 days the number had returned to normal. However, when the basal mineral salts solution was replaced by the high sodium chloride medium of Sugden (1953), the numbers decreased by over $95 \%$ in 2 days and the culture died. To determine whether the Sugden salt solution would support the protozoa, a fresh protozoal suspension from the rumen (prepared by the method of Coleman, 1958) was inoculated into Sugden salts with sulphide + rice starch +dried grass + fresh rumen fluid + chloramphenicol, using the general cultural methods described above and treated under condition $\mathbf{A}$ without dilution. Some protozoa were still alive after 5 weeks (when the experiment was discontinued) as compared with none after 15 days in Sugden's experiments.

\section{Attempts to stimulate growth under condition $A 2$}

The addition of $1 \mathrm{mg}$. Difco yeast extract/ml. produced an initial increase in the number of protozoa, but this was followed by heavy bacterial growth and death of the protozoa: $0.01 \mathrm{mg}$. yeast extract $/ \mathrm{ml}$. had no obvious effect. In view of the work of Kandatsu \& Takahashi (1956) who found that vitamin $\mathrm{B}_{12}$ stimulated the growth of Entodinia spp. from goat rumen, this compound was tested at $0 \cdot 3 \mu \mathrm{g} . / \mathrm{ml}$. but had no effect on the growth of the protozoa. A mixture of $\beta$-alanine, $p$-aminobenzoic acid, biotin (at $0.001 \mu \mathrm{g} . / \mathrm{ml}$.), calcium pantothenate, folic acid, nicotinamide, pyridoxin, riboflavin and thiamine (each at $0.01 \mu \mathrm{g}$. $/ \mathrm{ml}$.), tested with or without $0.3 \mu \mathrm{g}$. vitamin $B_{12} / \mathrm{ml}$. had no effect on the growth rate. The addition of maize starch, potato starch or wholemeal flour at $\mathbf{0 . 2 5} \mathrm{mg} . / \mathrm{ml}$. increased the small number of Metadinium medium present but had no stimulatory effect on the growth of Entodinium caudatum.

Further attempts to stimulate growth were made by increasing the dilution rate of the cultures. When the culture was diluted 2 days out of three under condition $A$, there were $5000-10,000$ protozoa $/ \mathrm{ml}$. on the second dilution day; only $4000 / \mathrm{ml}$. were present when the culture was diluted 3 days out of 4 under condition $\mathrm{D}$, but these numbers were constant over 90 days.

\section{Attempts to facilitate the maintenance of protozoa}

Initial experiments showed that to maintain the protozoa it was necessary to replace the supernatant fluid every $24 \mathrm{hr}$. by fresh complete medium. Later, the addition of grass and rice starch each day was found to maintain the organisms for periods of at least a week and that a culture on standard medium under condition A2 could be diluted without the preliminary centrifugation and replacement of supernatant fluid, i.e. changed to condition B2, with 
slight improvement in the growth rate. Further simplification in the procedure by changing to condition $\mathrm{D} 2$ produced a fall in the number of protozoa from $32,000 / \mathrm{ml}$. to $14,000 / \mathrm{ml}$. When no additions were made to the medium on non-dilution days under condition $\mathrm{D} 2$, the protozoa grew normally for 4 days but were dead after 8 days.

\section{Growth from a small inoculum}

In the experiments described above the minimum number of protozoa was usually greater than $10,000 / \mathrm{ml}$. and it was of interest to determine whether or not the protozoa would survive and multiply when less than 1000 protozoa $/ \mathrm{ml}$. were present. Figure 1 shows that when 900 protozoa $/ \mathrm{ml}$. were inoculated (as

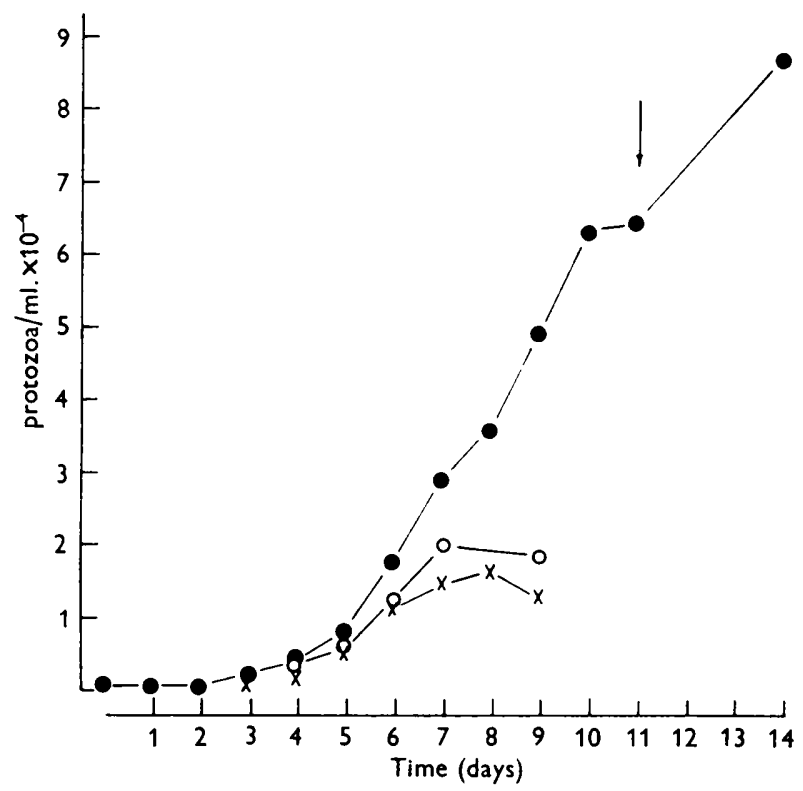

Fig. 1. Growth of Entodinia spp. from a small inoculum. The inoculum was 900 protozoa/ ml. added as $1.0 \mathrm{ml}$. culture grown on standard medium under condition A2. All media contained only $0.25 \mathrm{mg}$. rice starch $/ \mathrm{ml}$. except where indicated.

-0 inoculated into standard medium and maintained under condition A (using standard medium) without dilution; rice starch concentration increased to $0.5 \mathrm{mg} . / \mathrm{ml}$. at arrow. $\mathrm{O}-\mathrm{O}=$ inoculated into standard medium and maintained under condition $\mathrm{C}$ without dilution. $\times-x=$ inoculated into standard medium without chloramphenicol or rumen fluid and maintained under condition $C$ without dilution.

$\mathbf{1 . 0} \mathrm{ml}$. of a culture) into standard medium (containing rice starch at $\mathbf{0 . 2 5} \mathbf{m g}$./ $\mathrm{ml}$.) and treated under condition $\mathbf{A}$ without dilution, there was a short lag during which the numbers remained constant, but that thereafter each protozoan divided at least six times in 8 days. Good growth with only a slightly longer lag was obtained from as few as 100 protozoa $/ \mathrm{ml}$. The final yield of organisms $/ \mathrm{ml}$. was determined in part by the concentration of rice starch; doubling the concentration of rice starch increased the number of protozoa by 
$\mathbf{3 5} \%$ (Fig. 1). Similar results, but with slower growth rate and lower maximum population density, were obtained by inoculation of standard medium or standard medium without rumen fluid and chloramphenicol followed by treatment under condition $\mathrm{C}$ without dilution (Fig. 1). Cultures were regularly maintained under these three conditions by inoculating fresh medium each week with a $1.5 \%(\mathrm{v} / \mathrm{v})$ inoculum grown under the same conditions as that to be used for the inoculated tube; the average number of protozoa present on the seventh day is shown in Table 2. After maintenance for 25 weeks under either condition without daily replacement of supernatant fluid, 50-80\% of the protozoa were Entodinium longinucleatum; most of the remainder were E. caudatum.

The slower growth under condition $\mathrm{C}$ without dilution compared with condition A without dilution is probably associated with the heavier bacterial growth under the former condition.

\section{Table 2. Growth of Entodinia spp. from a small inoculum}

Entodinia maintained by weekly transfer using $1.5 \%(v / v)$ inoculum grown under the same conditions as those to be used for the inoculated tube. Culture 1 was maintained under condition A without dilution, with standard medium containing $0.25 \mathrm{mg}$. rice starch $/ \mathrm{ml}$. Culture 2 was inoculated into standard medium containing only $0.25 \mathrm{mg}$. rice starch $/ \mathrm{ml}$. and then maintained under condition $\mathrm{C}$ without dilution but adding rice starch to a concentration of $0.25 \mathrm{mg} . / \mathrm{ml}$. Culture 3 was the same as culture 2 except that chloramphenicol and fresh rumen fluid were omitted from the initial tube of medium.

$\begin{array}{ccc}\text { Culture } & \begin{array}{c}\text { No. of weekly } \\ \text { transfers }\end{array} & \begin{array}{c}\text { Average number } \\ \text { of protozoa/ml. } \\ \text { after growth for }\end{array} \\ 1 & 40 & 1 \text { week } \\ 2 & 41 & 38,000 \\ 3 & 27 & 18,000 \\ & & 10,000\end{array}$

\section{DISCUSSION}

As far as the author is aware, the present studies report the first successful attempts to maintain and grow Entodinia spp. from sheep rumen in vitro. The medium differed from that used unsuccessfully by Sugden (1953) in that: (a) the mineral salt solution was well buffered and rich in potassium instead of sodium; $(b)$ the starch and dried grass were not heated at $140^{\circ}$ for $1 \mathrm{hr}$. before addition to the medium. The successful result of inoculating fresh protozoa from the rumen into Sugden's salt solution suggests that, although the experimental conditions were not exactly comparable with those of Sugden, the salts plus rice starch, grass, rumen fluid and chloramphenicol would maintain the protozoa. It seems not improbable that the reason for Sugden's failure was the use of heated starch and hay. Heating the rice starch and grass at $140^{\circ}$ for $1 \mathrm{hr}$. produced a slight charring of both reagents and caused the dry powdery starch to form lumps. It is possible that the products of this charring reaction were either toxic to the protozoa or their essential bacteria or that they encouraged the growth of unfavourable bacteria. This latter possibility is supported by the observation that when heated rice starch and grass are 
added in the standard medium, the contents of the tube form a thick slimy deposit in 2 or 3 days.

The success of the present studies may be also attributed to the presence of chloramphenicol in the medium. This antibiotic partially suppressed the growth of the bacteria in the fresh rumen fluid but allowed some bacterial growth. When the fresh rumen fluid was replaced by autoclaved rumen fluid bacteria were still present, and it is likely that these were chloramphenicol resistant. In view of the finding of Gutierrez \& Davis (1959) that Entodinia spp. ingest Streptococcus bovis and possibly require that bacterium for growth, it is possible that the chloramphenicol in the present experiments suppressed bacteria harmful to the protozoa while allowing favourable bacteria to survive. Heavy bacterial growth was always associated with slower protozoal growth and decrease in the yield of organisms $/ \mathrm{ml}$.

Experiments are now in progress to improve the maintenance of the protozoa and to grow the organisms in axenic culture.

I wish to thank Dr J. M. Eadie for the loan of translations of the Japanese papers quoted and Miss C. M. Tebbutt and Miss J. M. How for their valuable technical assistance.

\section{REFERENCES}

Becker, E. R., Schultz, J. A. \& Emmerson, M. A. (1929). Experiments on the physiological relationships between the stomach infusoria of ruminants and their hosts, with a bibliography. Iowa St. Coll. J. Sci. 4, 215.

Bhatia, B. L. (1936). The Fauna of British India. Protozoa-Ciliophora. London: Taylor and Francis.

Coleman, G. S. (1958). Maintenance of oligotrich protozoa from the sheep rumen in vitro. Nature, Lond. 182, 1104.

Gutierrez, J. \& Davis, R. E. (1959). Bacterial ingestion by the rumen ciliates Entodinium and Diplodinium. J. Protozool. 6, 222.

Hungate, R. E. (1942). The culture of Eudiplodinium neglectum with experiments on the digestion of cellulose. Biol. Bull., Woods Hole, 83, 303.

Hungate, R. E. (1943). Further experiments on cellulose digestion by the protozoa in the rumen of cattle. Biol. Bull., Woods Hole, 84, 157.

Kandatsu, M. \& Takahashi, N. (1955a). Studies on reticulo-rumen digestion. Part 2. On the artificial culture of some Entodinia. I. J. Agric. Chem. Soc., Japan, 29, 833.

Kandatsu, M. \& Takahashi, N. (1955b). Studies on reticulo-rumen digestion. Part 3. On the artificial culture of some Entodinia. II. J. Agric. Chem. Soc., Japan, 29, 915.

KandaTsu, M.\&TAKahashi, N.(1956). Studies on reticulo-rumen digestion. Part 4. On the artificial culture of some Entodinia. III. J. Agric. Chem. Soc., Japan, 30, 96.

McPherson, M. J. (1953). Isolation and identification of amylolytic Streptococci from the rumen of the sheep. J. Path. Bact. 66, 95.

Margolin, S. (1930). Methods for the cultivation of cattle ciliates. Biol. Bull., Woods Hole, 59, 301.

Stone, H. W. \& Beeson, C. (1936). Preparation and storage of standard chromous sulphate solution. Industr. Engng Chem. (Anal.), 8, 188.

Sugden, B. (1953). The cultivation and metabolism of oligotrich protozoa from the sheep's rumen. J. gen. Microbiol. 9, 44.

Westphal, A. (1934). Studien über Ophryoscoleciden in der Kultur. Z. Parasitenk. 7,71 .

(Received 2 October 1959) 